\title{
Effects of Far-Infrared Irradiative Heating Pasteurization on Fungi
}

\author{
Tubasa Nakata, Arisa Okamoto, Jun Sawai*, Mikio Kikuchi \\ Faculty of Applied Bioscience, Kanagawa Institute of Technology, Atsugi, Japan \\ Email: sawai@bio.kanagawa-it.ac.jp
}

Received 23 June 2015; accepted 11 July 2015; published 14 July 2015

Copyright (C) 2015 by authors and Scientific Research Publishing Inc.

This work is licensed under the Creative Commons Attribution International License (CC BY). http://creativecommons.org/licenses/by/4.0/

(c) $\underset{\mathrm{EY}}{\mathrm{B}}$ Open Access

\section{Abstract}

The effect of far-infrared (FIR) irradiation pasteurization on fungi was quantitatively evaluated and compared with the effect of thermal conductive heating. After the bulk temperature of the sterile saline irradiated by FIR reached a steady given temperature, yeast cells (Candida albicans NBRC 1950 and Saccharomyces cerevisiae NBRC 1067) or fungal spores (Aspergillus niger NBRC 4781) were inoculated and FIR heating was conducted. A mullite cylinder FIR heater, with a main wavelength of $4-7 \mu \mathrm{m}$, was used for FIR heating. Death of fungi by FIR heating and by thermal conductive heating both followed first-order reaction kinetics, and the apparent death rate constants under different temperature conditions were obtained. For the same bulk temperatures, pasteurization by FIR heating was more effective than thermal conductive heating. The activation energy for the death of fungi by FIR irradiation was slightly lower than thermal conductive heating, indicating differences in the mechanism of action.

\section{Keywords}

Far-Infrared, Radiative Heating, Thermal Conductive Heating, Death Rate Constant, Yeast, Fungal Spore

\section{Introduction}

Infrared (IR) radiation is easily absorbed by water and organic materials. IR heating is used widely for the drying, dehydration, blanching, thawing and pasteurization [1]-[5], as well as for medical treatment [6] [7]. The importance of microbial decontamination is increasing owing to outbreaks of food poisoning and the emergence of drug-resistant bacteria. As well as providing clean working areas, IR heating can save space because no heattransfer medium is needed. Although the IR radiation cannot penetrate deep and heats up only a few millimeters

*Corresponding author. 
below the surface of the sample, the main effect of IR is due to heating of a thin layer of food material on the surface [5]. The IR heating process improves the shelf life of foodstuffs [8] [9], and is a promising method for the efficient inactivation of microbes [10]-[12]. During IR heating operations such as drying, blanching, roasting frying and cooking of food products, the pasteurization has progressed at the same time.

Previous studies have reported the use of IR, especially far-infrared (FIR), for pasteurization [13]-[20]. Compared with thermal conductive heating, FIR irradiation was found to be more effective in pasteurizing vegetative bacterial cells [13] [16] [20]. Furthermore, FIR irradiation caused heat activation and death of Bacillus subtilis spores in a temperature range where spore viability was not affected by thermal conductive heating [17]. Hamanaka et al. [21] also reported heat activation and the inactivation of bacterial spores by FIR irradiation. The pasteurization effects of FIR may be attributed to the absorption of radiative energy by the bacterial suspension in a very thin layer near the surface and an increase in the bulk temperature of the suspension [14] [18]. Although the effectiveness and validity of IR heating were confirmed in these studies, a quantitative evaluation of the FIR pasteurization effect against fungi was not performed, and pasteurization kinetics of fungi by FIR heating were not elucidated. In the present study, we evaluated the disinfection and pasteurization of liquid media and investigated the pasteurization kinetics of fungi suspended in saline by FIR heating under isothermal conditions.

\section{Materials and Methods}

\subsection{Test Organisms}

Candida albicans NBRC 1950, Saccharomyces cerevisiae NBRC 1067 and Aspergillus niger NBRC 4781 were purchased from the Biological Resource Center, National Institute of Technology and Evaluation (NBRC; Kazusa, Japan). Yeasts and a filamentous fungus were subcultured on Potato Dextrose Agar (PDA; Eiken Chemicals, Tokyo, Japan) slants at $25^{\circ} \mathrm{C}$ for 7 and 10 days, respectively, then stored at $4^{\circ} \mathrm{C}$.

Yeast colonies on the PDA slant were inoculated to Dextrose-Peptone broth (Eiken Chemicals) and incubated at $25^{\circ} \mathrm{C}$ for $24 \mathrm{~h}$. The yeast cells were washed and resuspended with sterile saline containing $0.1 \%$ peptone to yield a microbial concentration of approximately $10^{8} \mathrm{CFU} / \mathrm{ml}$.

The spores of $A$. niger that formed on the PDA slant were collected by adding $10 \mathrm{ml}$ of sterile saline containing $0.1 \%$ peptone to the test tube. The concentration of collected spores was measured with a PA2000 particle analyzer (Erma Inc., Tokyo, Japan) and adjusted to a concentration of approximately $10^{6}$ spores $/ \mathrm{ml}$.

\subsection{FIR Heating}

The FIR irradiation apparatus is displayed in Figure 1(a). A mullite cylinder FIR heater $\left(300 \times 15 \mathrm{~mm}^{2}\right.$; range of main wavelength is 4 - $7 \mu \mathrm{m}$, Higano Co., Soka, Japan) with a reflector was placed at the top [18]. The pasteurization temperature was controlled by varying the electric power and the distance between the heater and the

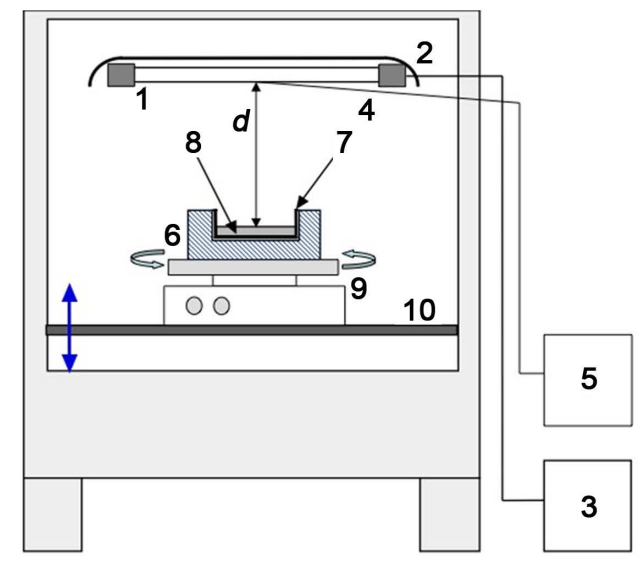

(a)

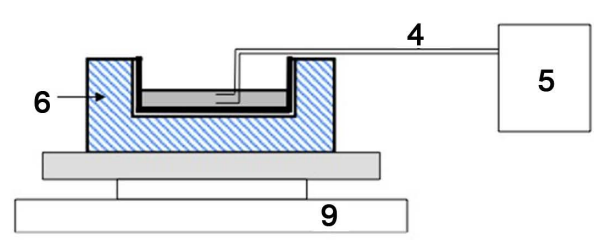

(b)

Figure 1. (a) Schematic diagram of the apparatus for FIR heating; (b) Measurement of temperature of microbial suspension. 1: heater; 2: reflector; 3: slidac; 4: thermocouple; 5: recorder; 6: insulator; 7: stainless steel Petri dish, 8: microbial suspension; 9: rotary shaker; 10: stage. 
surface of the liquid. Sterile saline $(30 \mathrm{ml})$ was dispensed into a stainless steel Petri dish $\left(14.5 \times 88.5 \mathrm{~mm}^{2}\right)$. The side wall and bottom of the Petri dish were thermally insulated, and the insulator was covered with aluminum foil to reflect FIR irradiation. Power was supplied to the heater. The Petri dish was placed under the FIR heater and irradiated while being agitated by a rotary shaker at $180 \mathrm{rpm}$. The bulk temperature became constant after a 15 -min irradiation in the case of the volume of saline of $30 \mathrm{ml}$ (the thickness of the liquid layer was $4.3 \mathrm{~mm}$ at rest). The yeast cell or spore solution was injected into the saline at $15 \mathrm{~min}$ and the IR pasteurization started ( $t=$ 0 ). Following irradiation, the dish containing the microbial suspension was removed from the apparatus and rapidly cooled on crushed ice. The cooled suspension was diluted with saline and then spread on PDA plates. Triplicate plates were prepared for each dilution. Colonies were counted after a $3 \mathrm{~d}$ or $5 \mathrm{~d}$ incubation at $25^{\circ} \mathrm{C}$ for yeasts or A. niger, respectively.

The temperature of the microbial suspension heated by FIR was measured by CA-thermocouples sheathed by a stainless steel tube $(0.25 \mathrm{~mm})$. The thermocouples were placed horizontally at a position close to the surface and at the bottom of the suspension (Figure $1(\mathrm{~b})$ ). The temperature difference was within $1^{\circ} \mathrm{C}$.

\subsection{Thermal Conductive Heating}

The thermal conductive heating apparatus has been previously described [13]. The temperature of the water bath shaker was set to the specified temperature, and a test tube containing saline $(10 \mathrm{ml})$ was immersed and shaken at 110 strokes/min in the water bath. When the temperature of the saline inside the test tube became the same as the temperature of the water bath, the yeast or spore solution $(0.1 \mathrm{ml})$ was added to the test tube. After heating, the tube containing the microbial suspension was removed, cooled in ice water, diluted and incubated as described in Section 2.2.

\subsection{Statistical Analysis}

All experiments were carried out at least in duplicate on three different occasions. Data points with bars represent means \pm standard error. Analysis of significant difference was compared by one-way ANOVA using IBM SPSS Statistics. The probability level interpreted as statistically significant was $P<0.05$.

\section{Results}

Figure 2 shows the effect of the bulk temperature on the viability of $C$. albicans heated by FIR irradiation. The ordinate is the ratio of the $C$. albicans CFU post-irradiation $(N)$ divided by the non-treated CFU $\left(N_{0}\right)$. The effect tiveness of pasteurization by FIR heating increased with the bulk temperature of the irradiated suspension. As shown in Figure 2, with the logarithmic survival ratio and irradiation time $(t)$ as the ordinate and abscissa, respectively, the population of the C. albicans decreased almost linearly at a constant temperature. Thus, assuming that the pasteurization of $C$. albicans by FIR irradiation follows first-order reaction kinetics as given by Equation (1) [22], the apparent first-order death rate constant, $k$, of $C$. albicans by FIR heating can be determined.

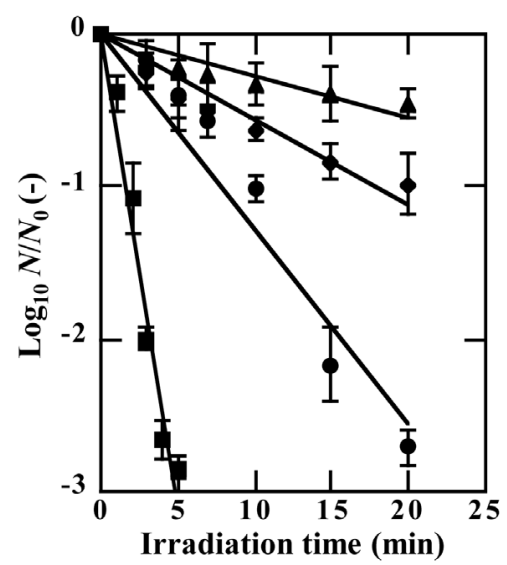

Figure 2. Effect of bulk temperature on pasteurization of $C$. albicans in FIR-irradiated suspensions. Symbols: $48^{\circ} \mathrm{C} ; \bullet, 50^{\circ} \mathrm{C} ; \bullet, 52^{\circ} \mathrm{C} ; \bullet, 54^{\circ} \mathrm{C}$. Data points with bars represent means \pm standard error $(\mathrm{n}=3)$. 


$$
\log \left(N / N_{0}\right)=-(k / 2.303) \times t
$$

Figure 3 summarizes the $k$ values obtained under different conditions in an Arrhenius plot. Here, $T$ represents the bulk temperature of the microbial suspension heated by FIR irradiation or thermal conduction. At lower temperatures, $k$ values for FIR heating were larger than those for thermal conductive heating. A similar trend was observed for $S$. cerevisiae and A. niger.

\section{Discussion}

Assuming that the $k$ values followed the Arrhenius equation as shown by Equation (2) [22]

$$
k=A \exp \left(-E_{a} / R T\right)
$$

the activation energy $\left(E_{a}\right)$ for the death of fungi used in this study by FIR and thermal conductive heating was determined (Table 1). Compared with the thermal conductive heating, the values of $E_{a}$ for the IR irradiation decreased, indicating that FIR heating is superior to thermal conductive heating in energy expenditure. Ward et al. [23] investigated the pasteurization effectiveness of a high-power Nd:YAG laser light (1.064 $\mu \mathrm{m})$, which emits energy in the IR wavelength range, on E. coli in saline and reported that the action of the Nd:YAG laser light at $50^{\circ} \mathrm{C}$ was due partly to thermal heating and partly to an additional, undefined mechanism. Hamanaka et al. [24] hypothesized that inactivation of microorganisms by IR heating may involve an inactivation mechanism similar to that of UV light (DNA damage) and microwave heating in addition to thermal effects. Previous reports have evaluated stress-induced injury in bacteria on the basis of the sensitivity changes to antibiotics. The validity of this method was examined using chemical and physical stresses [16]. Although similar sensitivity changes were obtained from thermal conductive heating and IR heating, the damage caused by IR heating was more serious than that caused by thermal conductive heating [16]. Krishnamurthy [25] verified the cell wall damage, cytoplasmic membrane shrinkage, cellular content leakage and mesosome disintegration of IR-treated S. aureus.

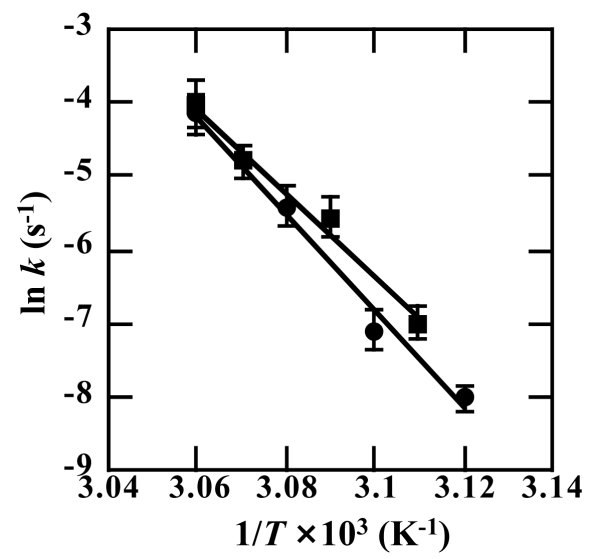

Figure 3. Arrhenius plot of death rate constants of $C$. albicans by FIR heating and thermal conductive heating. $T$ presents the bulk temperature of the microbial suspension heated by FIR irradiation or thermal conduction. Symbols: $\mathbf{m}$ IR; $\bullet$, thermal conductive heating; lines, the regression line calculated by the Equation (2). Data points with bars represent means \pm standard error $(n=3)$.

Table 1. Values of activation energy $\left(E_{\mathrm{a}}\right)$ of inactivation of fungi by FIR heating and thermal conductive heating.

\begin{tabular}{ccc}
\hline & \multicolumn{2}{c}{$E_{\mathrm{a}} \times 10^{-5}(\mathrm{~J} / \mathrm{mol})$} \\
\cline { 2 - 3 } Microorganisms & FIR & Thermal conduction \\
\hline C. albicans & $4.7 \pm 0.4^{\mathrm{a}}$ & $5.7 \pm 0.5^{\mathrm{b}}$ \\
S. cerevisiae & $4.6 \pm 0.6^{\mathrm{a}}$ & $6.0 \pm 0.5^{\mathrm{b}}$ \\
A. niger & $9.1 \pm 0.3^{\mathrm{c}}$ & $11.3 \pm 0.4^{\mathrm{d}}$ \\
\hline
\end{tabular}

Different letters indicate significant difference $(P<0.05)$. 
In a previous study [14] [15], temperature distribution of the bacterial suspension irradiated by IR was estimated; it was proposed that the temperature in a thin surface region, which cannot be measured by thermocoupling, was higher than the temperature of the bulk suspension. For example, when the irradiated power was $3.22 \mathrm{~kW} / \mathrm{m}^{2}$, the estimated surface temperature of the suspension rose to approximately $57^{\circ} \mathrm{C}$ for $0.3 \mathrm{~s}$, even when the bulk temperature of the suspension was maintained at $40^{\circ} \mathrm{C}$ [14]. Thus, bacteria circulating in the suspension will be subjected to repeated episodes of rapid temperature fluctuations as they pass into and out of the surface region. The accumulated effect of this repeated stress might cause $E$. coli damage and death, even when the bulk temperature of the suspension irradiated by IR remains below the lethal temperature [18]. Therefore, variation in the thickness of the liquid layer affects the frequency and duration of bacterial cell contact with the surface region. In fact, the effectiveness of pasteurization by IR increased with a decrease in the thickness of the liquid layer, even at the same bulk temperature [20]. This difference, shown in Table 1, suggests that some mechanisms of action might be different, possibly because of the increase in the surface temperature and the direct absorption of IR radiative energy in the surface region of the liquid layer.

\section{Conclusion}

This study evaluated the pasteurization kinetics of fungi suspended in saline by FIR heating under isothermal conditions. For the same bulk temperatures, pasteurization by FIR heating was more effective than thermal conductive heating. The activation energy for the death of fungi by FIR irradiation was slightly lower than thermal conductive heating. This indicates differences in the mechanism of action. Although the understanding of the action mechanism is still unclear, IR heating can offer many advantages over conductive heating in heat transfer rate and heat flux, which results in time-savings as well as increased production line speed.

\section{References}

[1] Rosenthal, I., Rosen, B. and Bernstein, S. (1996) Surface Pasteurization of Cottage Cheese. Milchwissenschaft, 51, 198-201.

[2] Paakkonen, K., Havento, J., Galambosi, B. and Pyykkonen, M. (1999) Infrared Drying of Herb. Agricultural and Food Science in Finland, 8, 19-27.

[3] Mongpraneet, S., Abe, T. and Tsurusaki, T. (2002) Accelerated Drying of Welsh Onion by Far Infrared Radiation under Vacuum Conditions. Journal of Food Engineering, 55, 147-156. http://dx.doi.org/10.1016/S0260-8774(02)00058-4

[4] Krishnamurthy, K., Khurana, H.K., Soojin, J., Irudayaraj, J. and Demirci, A. (2008) Infrared Heating in Food Processing: An Overview. Comprehensive Reviews in Food Science and Food Safety, 7, 2-13. http://dx.doi.org/10.1111/j.1541-4337.2007.00024.x

[5] Rastogi, N.K. (2012) Recent Trends and Developments in Infrared Heating in Food Processing. Critical Reviews in Food Science and Nutrition, 52, 737-760. http://dx.doi.org/10.1080/10408398.2010.508138

[6] Hatayama, H., Inoue, A. and Kato, J. (2008) Study on Use of Blue-Violet Laser Diode Module as Dental/Oral Surgical Device. SEI Technical Review (English Edition), 66, 142-146.

[7] Tuchina, E.S., Petrov, P.O., Kozina, K.V., Ratto, F., Centi, S., Pini, R. and Tuchin, V.V. (2014) Using Gold Nanorods Labelled with Antibodies under the Photothermal Action of NIR Laser Radiation on Staphylococcus aureus. Quantum Electronics, 44, 683. http://dx.doi.org/10.1070/QE2014v044n07ABEH015497

[8] Ha, J.W. and Kang, D.H. (2015) Enhanced Inactivation of Food-Borne Pathogens in Ready-to-Eat Sliced Ham by Near-Infrared Heating Combined with UV-C Irradiation and Mechanism of the Synergistic Bactericidal Action. Applied and Environmental Microbiology, 81, 2-8. http://dx.doi.org/10.1128/AEM.01862-14

[9] Wang, B., Khir, R., Pan, Z., El-Mashad, H., Atungulu, G.G., Ma, H., McHugh, T.H. Qu, W. and Wu, B. (2014) Effective Disinfection of Rough Rice Using Infrared Radiation heating. Journal of Food Protection, 77, 1538-1545. http://dx.doi.org/10.4315/0362-028X.JFP-14-020

[10] James, C., Lechevalier, V. and Ketteringham, L. (2002) Surface Pasteurization of Shell Eggs. Journal of Food Engineering, 53, 193-197. http://dx.doi.org/10.1016/S0260-8774(01)00156-X

[11] Ansari, I.A. and Datta, A.K. (2003) An Overview of Sterilization Methods for Packaging Materials Used in Aseptic Packaging Systems. Transactions of the Institution of Chemical Engineers, 81, 57-65. http://dx.doi.org/10.1205/096030803765208670

[12] Hebbar, H.U., Nandini, K.E., Lakshmi, M.C. and Subramanian, R. (2003) Microwave and Infrared Heat Processing of Honey and Its Quality. Food Science and Technology Research, 9, 49-53. http://dx.doi.org/10.3136/fstr.9.49 
[13] Hashimoto, A., Shimizu, M. and Igarashi, H. (1991) Effect of Far Infrared Radiation on Pasteurization of Bacteria Suspended in Phosphate-Buffered Saline. Kagaku Kogaku Ronbunshu, 17, 627-633. (In Japanese) http://dx.doi.org/10.1252/kakoronbunshu.17.627

[14] Hashimoto, A., Sawai, J., Igarashi, H. and Shimizu, M. (1992) Effect of Far-Infrared Irradiation of Pasteurization of Bacteria Suspended in Liquid Medium below Lethal Temperature. Journal of Chemical Engineering of Japan, 25, 275-281. http://dx.doi.org/10.1252/jcej.25.275

[15] Hashimoto, A., Sawai, J., Igarashi, H. and Shimizu, M. (1993) Irradiation Power Effect of IR Pasteurization below Lethal Temperature of Bacteria. Journal of Chemical Engineering of Japan, 26, 331-333. http://dx.doi.org/10.1252/jcej.26.331

[16] Sawai, J., Sagara, K., Igarashi, H., Hashimoto, A., Kokugan, T. and Shimizu, M. (1995) Injury of Escherichia coli in Physiological Phosphate-Buffered Saline Induced by Far-Infrared Irradiation. Journal of Chemical Engineering of Japan, 28, 294-299. http://dx.doi.org/10.1252/jcej.28.294

[17] Sawai, J., Fujisawa, M., Igarashi, H., Hashimoto, A., Kokugan, T., Shimizu, M. and Kojima, H. (1997) Pasteurization of Bacterial Spores in Liquid Medium by Far-Infrared Irradiation. Journal of Chemical Engineering of Japan, 30, 170-172. http://dx.doi.org/10.1252/jcej.30.170

[18] Sawai, J., Sagara, K., Kasai, S., Igarashi, H., Hashimoto, A., Kokugan, T., Shimizu, M. and Kojima, H. (2000) FarInfrared Irradiation-Induced Injuries to Escherichia coli at below the Lethal Temperature. Journal of Industrial Microbiology and Biotechnology, 24, 19-24. http://dx.doi.org/10.1038/sj.jim.2900772

[19] Sawai, J., Sagara, K., Hashimoto, A., Igarashi, H. and Shimizu, M. (2003) Inactivation Characteristics Shown by Enzymes and Bacteria Treated with Far-Infrared Radiative Heating. International Journal of Food Science \& Technology, 38, 661-667. http://dx.doi.org/10.1046/j.1365-2621.2003.00717.x

[20] Sawai, J., Isomura, H., Honma, T. and Kenmochi, H. (2006) Characteristics of the Inactivation of Escherichia coli by Infrared Irradiative Heating. Biocontrol Science, 11, 85-90. http://dx.doi.org/10.4265/bio.11.85

[21] Hamanaka, D., Uchino, T., Hu, W., Tanaka, S. and Aramaki, S. (2003) Effects of Infrared Radiation on Inactivation and Injury of B. subtilis and B. pumilus Spores. Nippon Shokuhin Kagaku Kogaku Kaishi, 50, 51-56. (In Japanese) http://dx.doi.org/10.3136/nskkk.50.51

[22] Aiba, S., Humphery, A.E. and Mills, N.F. (1973) Biochemical Engineering. 2nd Edition, Academic Press, New York, 239-344.

[23] Ward, G.D., Watson, I.A., Stewart-Tull, D.E., Wardlaw, A.C., Wang, R.K., Nutley, M.A. and Copper, A. (2000) Bactericidal Action of High-Power Nd:YAG Laser Light on Escherichia coli in Saline Suspension. Journal of Applied Microbiology, 89, 517-525. http://dx.doi.org/10.1046/j.1365-2672.2000.01144.x

[24] Hamanaka, D., Dokan, S., Yasunaga, E., Kuroki, S., Uchino, T. and Akimoto, K. (2000) The Sterilization Effect on Infrared Ray of the Agricultural Products Spoilage Microorganisms (Part 1). 2000 ASAE Annual Meeting International, Milwaukee, 9-12 July 2000, 1-9.

[25] Krishnamurthy, K. (2006) Decontamination of Milk and Water by Pulsed UV Light and Infrared Heating. PhD Thesis, The Pennsylvania State University, State College. 